\title{
Hibridismo cultural e atualização da cultura: o Carimbó do Brasil
}

\section{Cultural hybridism and update of culture: the Carimbó of Brazil}

\author{
Silvio Lima Figueiredo' \\ slima@ufpa.br \\ Eliana Bogéa \\ elianabogea@ufpa.br
}

\section{Resumo}

A cultura popular deve ser estudada a partir de seu dinamismo, relacionada às diversas sociedades por todo mundo e suas transformações. A globalização hoje é impossível de ser negada, e a forma como a cultura popular se comporta atualmente é um tema importante, haja vista as diversas teorias que transformam o viés excludente da globalização em possibilidade de agregação e até inclusão. Várias categorias já trataram do assunto: mudança cultural, aculturação, fricção interétnica, e todas as categorias criadas para designar fenômenos similares, indicam como esse tema foi interpretado ao longo dos anos. Ao se estudar a mudança cultural, deparamo-nos com a problemática de identificar o externo em sociedades que não são fechadas e homogêneas, e que não se caracterizam como comunidades puras. Num mundo globalizado, onde estariam as sociedades desse tipo hoje em dia? $\mathrm{O}$ trabalho pretende compreender essa dinâmica, a partir da ideia de atualização, através de estudos da Cultura Popular na Amazônia brasileira.

Palavras Chave: Cultura popular; Hibridismo cultural; Carimbó.

\section{Abstract}

To deal with popular culture in a postmodern approach is to address the dynamism of culture and society in different points around the world. If it is impossible to deny globalization, the way popular culture is currently expressed is a necessary theme, given the theories concerning postmodernism that currently turn an initial concept of opposition into a concept of aggregation or inclusion. The discussion regarding cultural transformation, acculturation, interethnic friction and all categories created to describe similar phenomena, reflects a history of how this issue was interpreted. While coping with this subject, we are challenged with another issue of equal significance: how could one identify the external matters in a society that is not closed, nor homogeneous, and which is not characterized as a community in its purest concept? Moreover, where would such societies be nowadays in a globalized world? The present article aims to understand this dynamic, calling it an update by means of research with focus on Popular Culture in Brazilian Amazon region.

Keywords: Popular culture; Cultural hybridism; Carimbó.

\footnotetext{
1 Professor e pesquisador do Núcleo de Altos Estudos Amazônicos da Universidade Federal do Pará (NAEA/UFPA). Doutor em Comunicação (ECA/USP), com estágio pós-doutoral em Sociologia na Université René Descartes - Paris V Sorbonne. Pesquisador do CNPq. 2 Doutoranda do (NAEA/UFPA).
} 


\title{
Mudança cultural e possibilidades teóricas da atualização da cultura
}

\author{
Se en soubesse que tu vinhas, \\ Eu fazia o dia maior, \\ Dava um nó na fita verde \\ Praprender o raio de sol
}

Mestre Lucindo

Tratar a chamada cultura popular na atualidade é abordar o dinamismo da cultura e da sociedade em vários pontos do planeta. Se, de um lado, é impossível negar a globalização, entendida aqui como dimensão que conecta de diversas formas as sociedades mundiais, de outro, é necessário saber como a chamada cultura popular se comporta nesse cenário, haja vista as teorias que atualmente transformam um conceito inicialmente baseado em oposição (como foi e continua sendo a globalização), em um conceito de agregação ou inclusão.

A discussão da mudança cultural, aculturação, fricção interétnica e todas as categorias criadas para designar fenômenos similares, traduz um histórico de como esse tema foi interpretado ao longo dos anos. Frente a essa questão, aparece outra de igual importância: como identificar o externo em uma sociedade que não é fechada, homogênea, que não se caracteriza como comunidade na sua conceituação mais pura? E onde estariam as sociedades desse tipo hoje em dia, num mundo "globalizado"?

Com efeito, o presente trabalho pretende compreender essa dinâmica a partir da ideia de atualização no universo do carimbó, expressão da cultura popular na Amazônia brasileira. O carimbó, que envolve modos de viver (manifestação cultural e movimento social) e modos de faz̧er (expressão artística e cadeia produtiva), ocorre em todo o estado do Pará, porém se revela mais fortemente na Região do Salgado, litoral nordeste do estado, na Região Metropolitana de Belém (RMB), na Região do Guamá e na Ilha do Marajó. Como movimento cultural, símbolo da cultura tradicional e identidade paraense, é o núcleo da discussão deste trabalho, mais precisamente as ocorrências nas cidades de Belém, capital paraense, e Soure, na Ilha do Marajó, pelo seus processos de patrimonialização e por seu uso turístico e pela indústria cultural.

As categorias tradicionais no estudo da mudança cultural são importantes para qualquer análise do tema. Por algum tempo, esses fenômenos eram estudados através do conceito de aculturação, qual seja, "um conjunto de fenômenos que resulta do contato direto e contínuo entre grupos de culturas diferentes, o que acarreta mudanças subsequentes nos tipos culturais de cada grupo" (ORTIZ, 1990, p. 12). Oliveira (1978), por sua vez, ao estudar as relações entre tribos indígenas, apresentou o conceito de fricção interétnica como o contato entre grupos étnicos irreversivelmente vinculados uns aos outros. A despeito das contradições expressas por meio de conflitos (manifestos) ou tensões (latentes) existentes entre si, utilizou conceitos como o de assimilação, segundo o qual um grupo étnico se incorpora noutro e, por isso, perde sua peculiaridade cultural e identificação étnica anteriores. No entanto, a depender de como são usados, esses conceitos possibilitam discussões mais densas sobre a questão do poder de um grupo sobre outro, no caso do autor em questão, sobre as relações entre tribos, e entre tribos e sociedade nacional, especificamente os Terêna no Mato Grosso do Sul.

Ao estudar os grupos indígenas do Alto Rio Negro (Amazonas), Ana Oliveira (1995, p. 31) nos coloca a seguinte questão: “aqui também se verifica o encontro de duas 'racionalidades' distintas, a local, configurada na população indígena e orientada por critérios de hierarquia mítica, e a nacional caracterizada pelo conjunto de interesses mobilizadores da opinião política regional". As transformações, para a autora, se dão principalmente na cultura dos indivíduos que são tomados por uma fronteira em expansão. Isso porque,

o conceito de rural passa a desempenhar o papel de guardião de um estoque simbólico definidor de uma história "antiga e atrasada", por oposição ao moderno contexto urbano. Convivem ali, todos os valores definidores da diversidade étnica original, de relações econômicas pouco modificadas pelo capitalismo, onde o trabalho se orienta por regras tradicionalmente consagradas por relação de parentesco e onde os grupos diferenciados entre si se esforçam por manter seu principal elemento de identificação étnica - a língua (OLIVEIRA, 1995, p. 116). 
Victor Turner (1974) propõe em seus estudos uma compreensão dessa questão a partir de oposições que se dariam entre conceitos de estrutura e communitas. Neste caso, a estrutura não só está dentro do grupo, como na verdade é o próprio grupo, representado pelo seu cotidiano, em oposição à communitas, os momentos liminares e ritualizados das festas e outras expressões que indicam comunhão. A estrutura está presente também nos aspectos externos à vida da própria comunidade, que interferem e alteram em certa medida a vida cotidiana ou sagrada. Nessa lógica, ao estudar a festa do Divino em Pirenópolis (GO), Brandão (1978) evidencia uma dicotomia entre tradição, a festa em si (organizadores e brincantes, por exemplo) e a mercantilização por meio da indústria cultural e do turismo, revelada, por exemplo, pela renovação promovida pela igreja católica. Assim, a oposição poderia ser compreendida como tradição interna versus comercialização, externa à festa. No entanto, é preciso ter muito cuidado com essa perspectiva, de olhar tais fatos a partir de oposições, pois isso pode nos levar a armadilhas, reduzindo e simplificando essas práticas, relações sociais e mudanças culturais, mesmo que as abordagens de Turner e Brandão não sigam nessa direção simplificadora.

Questionar/filtrar oposições aqui implicadas significa ultrapassá-las como fatores, um interno, que está lá, e um externo, que vem de fora e altera o que já existe, para alcançar questões cruciais: (i) as mudanças são contínuas e fazem parte da cultura como característica principal, assim como as normas de sua manutenção; (ii) as mudanças se produzem também internamente, sem a necessidade de intromissões externas; (iii) o que podemos classificar como externo é bastante relativo e de difícil definição em um mundo "globalizado"; (iv) as unidades culturais, representadas por identidades, passam por transformações inerentes à pós-modernidade.

Nessa chave, García Canclini (1983) aponta que relação entre cultura popular e pós-modernidade representa a inserção da economia capitalista na vida rural/indígena mexicana, exemplificada pela proletarização do artesão, comercialização do artesanato e espetacularização das festas pelo turismo. As culturas dos habitantes dos vilarejos estudados pelo autor, formados pelos descendentes dos índios, significaria a cultura popular em oposição à cultura hegemônica capitalista, produto de intersecções entre os conceitos de indígena, rural (em oposição a urbano) e popular.

\section{Carimbó, atualizạąão da cultura popular}

Expressão central da cultura paraense, o carimbó é descrito por Salles e Salles (1969, p. 278) como “dança de roda reunindo homens e mulheres, na qual os pares se destacam, um a um, e dançam soltos, aparecendo então configurações coreográficas solistas”. Em geral, o carimbó dançado em Soure, município da Ilha do Marajó,

é chamado de carimbó pastoril, dife-

Figura 1 - Regiões de incidência atual dos Grupos de Carimbó no Pará.

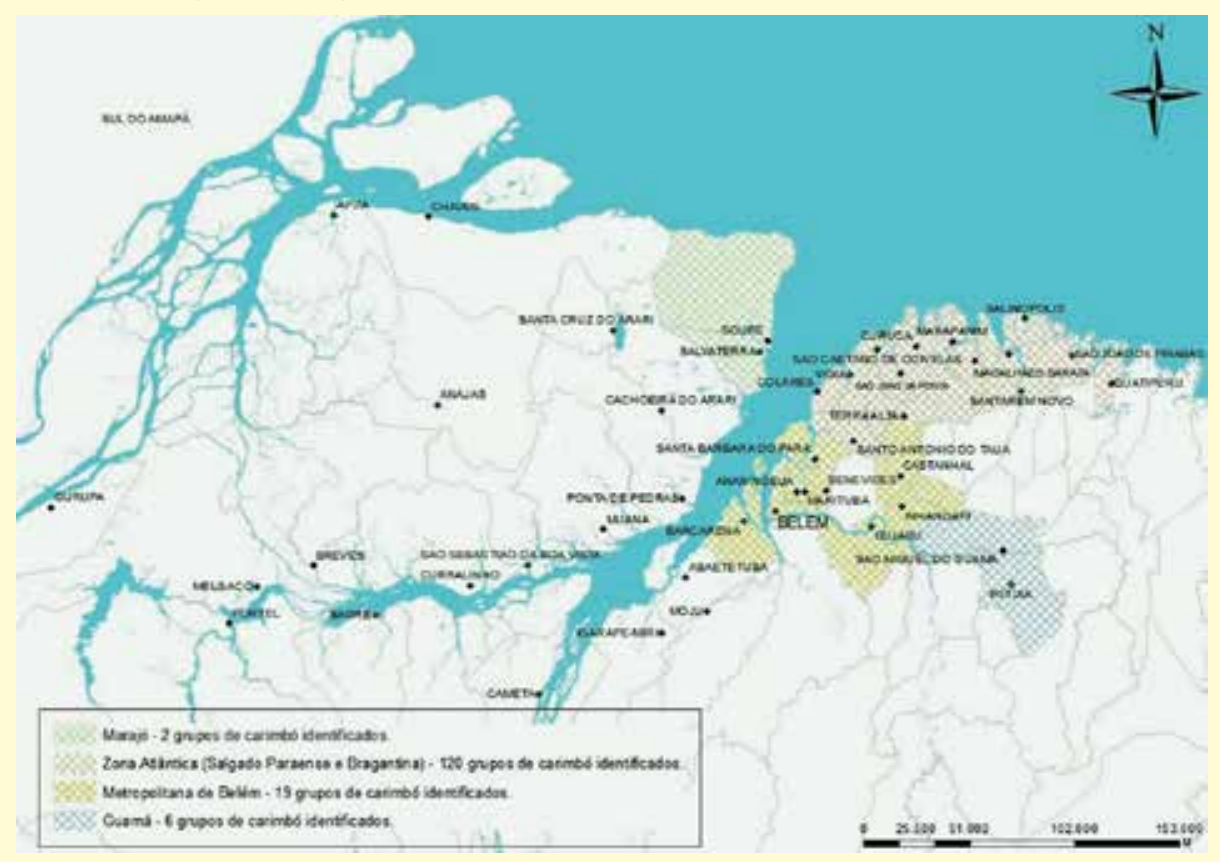

Fonte: Iphan (2013), adaptado no Laboratório de Análises Espaciais (NAEA/UFPA, 2015). rente do carimbó de Marapanim e Maracanã, municípios litorâneos do nordeste paraense, o carimbó praieiro. Com efeito, o carimbó integra a lúdica do caboclo, é lazer em primeiro lugar e sintetiza muito a identidade da cultura popular do Pará.

O termo carimbó nasceu da denominação dos tambores fabricados de troncos de árvores escavadas, com uma das extremidades coberta de pele de animal silvestre, que medem aproximadamente 1 metro de comprimento e variam entre 35 e 65 centímetros de diâmetro, chamados de curimbó (Imagem 1). Os conjuntos musicais utilizam de 2 a 3 curimbós, 
os mais longos para os sons agudos e o mais largo para os graves. Conforme Gabbay (2012, p. 55), é provável que o carimbó tenha surgido simultaneamente em diferentes territórios paraenses, então isolados entre si, nas regiões do Salgado, do Tapajós e do Marajó. "Eis o DNA do carimbó, o diálogo sincopado entre tambor e maraca, entre o negro e o índio", representado pelo curimbó, que estabelece o elo entre sujeito e objeto, entre passado e presente, para designar-lhe a denominação que o expressa.

Gabbay esclarece haver muito pouco registro sobre o nascimento do carimbó, e considera sua trajetória bastante dispersa:

De modo geral o batuque africano foi, provavelmente, a origem do carimbó e suas variações de estilo. Influências indígenas também podem ser percebidas em traços da coreografia (passos imitativos de figuras de animais nativos, como peru, bagre, galo e gambá, todos dão nome a coreografias de carimbó), versos (em nominações e dizeres típicos e ambientações da natureza) e música (com melodia às vezes mais horizontalizada com ritmo mais marcado e uníssono, além da marcante herança ibérica no bailado e em parte do instrumental) (GABBAY, 2012, p. 58).

Imagem 1 - Tambores utilizados no carimbó (2015).

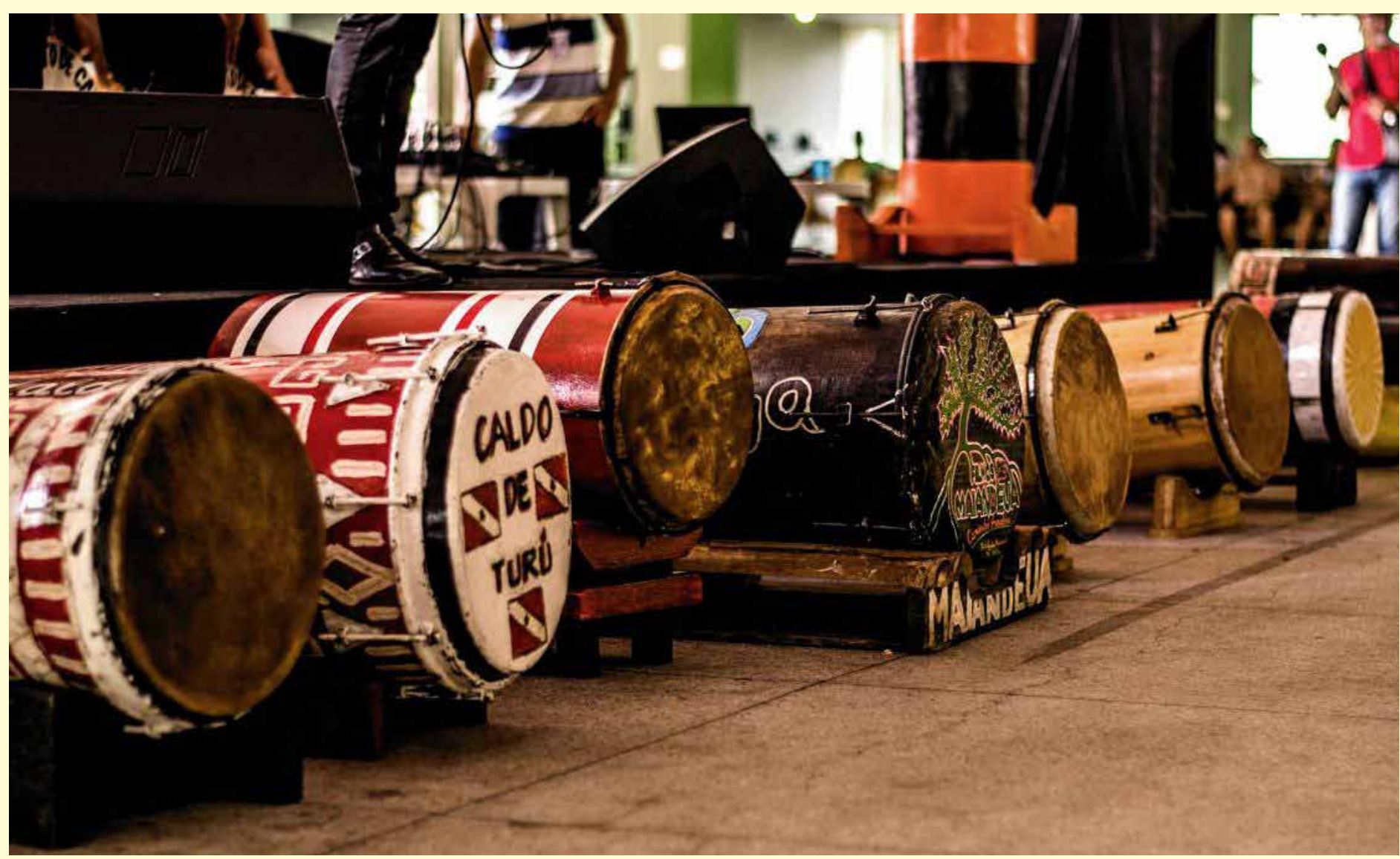

Fonte: Pierre Azevedo (acervo pessoal).

O Dossiê do Iphan (2013) para registrar o Carimbó como Patrimônio Imaterial Brasileiro reforça a ausência de documentos escritos sobre a história dessa manifestação, tanto quanto a necessidade de recorrer a fontes não escritas, principalmente àquelas da memória e da história oral de seus praticantes, seja pela experiência própria do narrador, seja pela memória herdada, reconhecida pela comunidade local. Ao considerar a diversidade intrínseca ao carimbó nas diferentes regiões do Pará, com especificidades próprias de cada uma das inúmeras comunidades que o mantêm vivo, chama atenção, nessa rede, uma experiência comum, um sentimento coletivo de pertencimento, uma identidade do que é "ser paraense".

Segundo Nazaré do Ó, "Era muito interessante duas negras de dois metros de altura, dona Ciana e dona Quitéria, mãe e tia de seu Pedro, eram centenárias, a dona Quitéria morreu com 124 anos, e dona Ciana, com 112 anos. Só para vocês terem uma ideia, elas eram africanas. É bom lembrar então o seu Pedro, banjista. E essas duas senhoras, 
elas sentavam no tambor, amarravam as saias grandes, as duas no tambor e toma-lhe Carimbó. Batiam Carimbó com um ritmo bem afinado. Eu lembro muito delas e lembro que a gente andava pelos caminhos de Icoaraci para chegar até as festas, até o Zimba. E quando eu cheguei no Tenoné, eles chamavam Zimba, a dança, a manifestação eles chamavam Zimba” (FIGUEIREDO; TAVARES, 2006, p. 137).

O Dossiê do Iphan (2013) apresenta também os territórios negros, conhecidos pelo título político de remanescente de quilombos, como uma referência comum sobre a gênese do carimbó. Outra seria a correlação existente entre carimbó e festa de santo:

\begin{abstract}
Mais especificamente esse vínculo com o sagrado é construído através da experiência de etnicidade que vincula homens negros ao santo negro. (...) A relação entre o carimbó e as festividades de santo é notadamente irredutível, do ponto de vista de sua reprodução, sobretudo, nas localidades interioranas, e este fato se torna mais significativo ao se levar em conta as celebrações em devoção a São Benedito, muitas vezes referenciado como o "santo do carimbó" (IPHAN, 2013, p. 82).
\end{abstract}

Figueiredo (1999), por sua vez, apresenta o carimbó como a sintese de folganças caboclas que associa trabalho e lazer, traduzidos nas situações cotidianas de suas letras. Proveniente do encontro do negro, da cultura dos povos da Amazônia, índios e caboclos, e das danças portuguesas, está presente em todo território paraense, porém com maior concentração na região do Salgado (zona atlântica):

\begin{abstract}
O carimbó é então compreendido como uma das formas de lazer do povo da região, que traz suas vivências cotidianas de trabalho para o âmbito dessa dança (...) a maioria dos estudos interpretam assim o carimbó, e assim ele foi dançado nas muitas festas realizadas pelas populações da Amazônia paraense. No entanto, em decorrência da atividade turística, podemos perceber algumas modificações. O carimbó agora já não é dançado nas festas da comunidade, mas realizado nos salões dos hotéis ou em festivais programados; o lazer do caboclo já é agora trabalho, pois ele dança para ganhar dinheiro (cada apresentação é paga); o ritmo torna-se rápido; os turistas são chamados a participar; enfim, o que antes era lazer, dançado em todas as festas, transforma-se em espetáculo, em que cada apresentação precisa de uma produção ainda que pequena. $\mathrm{O}$ turismo com certeza transforma o brincante em componente de grupo parafolclórico, em trabalhador (FIGUEIREDO, 1999).
\end{abstract}

Interpreta-se o carimbó, muitas vezes no senso comum, como ritmo indígena, mas sua origem negra é evidente, como indica a música "A Ilha de Marajó", do Mestre Verequete, nos versos "Ela, ela, ela a maior ilha do nosso Pará/ a Ilha de Marajó/ tem grande povoação/ aonde nasceu o carimbó/ no tempo da escravidão". Como uma espécie de ritmo caboclo, proveio das relações do negro e dos povos da Amazônia, índios e caboclos, somado às danças portuguesas. Segundo Salles e Salles (1969), "o carimbó enquanto dança e enquanto música é uma das formas mais puras e significativas do lazer popular. O divertimento que mais anima as populações dessa região". É uma folgança "cabocla", que associa trabalho e lazer, cujas letras remetem a cenas da vida cotidiana e do trabalho. Como afirma Maciel (1983, xviii), "a poesia do carimbó é comprometida com a vida, com o amor, com as vicissitudes, as lides diárias, a natureza e todo o mundo natural do homem interiorano paraense".

Interpretada como dança típica paraense, o carimbó é facilmente encontrado no hall dos hotéis e pousadas, é dançado pelos grupos parafolclóricos, cujo trabalho depende em grande medida dos turistas. Formam esses grupos os tocadores, que cantam toadas de autoria própria ou de outros compositores, e os dançarinos, que formam pares e respondem igualmente pela coreografia e evolução de danças regionais como siriá, xote e chula, além do carimbó. O turismo é o principal nicho de atuação dos grupos parafolclóri$\cos ^{3}$, além das apresentações em eventos dos órgãos oficiais de cultura e turismo, como as festas juninas e o Círio de Nossa Senhora Nazaré4. Descontinuamente aparecem na mídia regional como produto da indústria

3 Integram as programações dos passeios turísticos em barcos na Baia do Guajará, na orla de Belém, quase que diariamente.

4 Grande festa processional paraense, Patrimônio Cultural Imaterial Brasileiro, categoria celebração, registrado pelo Iphan em 2004 (FIGUEIREDO, 2005). 
Dossiê

cultural, por exemplo em gravações de "cantores da terra", alguns consagrados regional e nacionalmente, como Pinduca, Nilson Chaves e Fafá de Belém, e apresentam-se também nas casas noturnas da capital paraense, com períodos de maior ou menor sucesso.

Mestre Verequete, Mestre Cupijó e Mestre Lucindo foram alguns dos expoentes do carimbó e de expressões próximas, como o siriá, e foram assim chamados porque são os compositores e tocadores mais antigos do carimbó pau e corda ${ }^{5}$, e como tais ocasionalmente aparecem na agenda oficial do poder público estadual e/ou municipais. No Marajó, as letras de Mestre Biri, por exemplo, demonstram similaridade com o carimbó mais antigo ao cantar os aspectos da vida marajoara:

$$
\begin{aligned}
& \text { O pica-pau quando pica } \\
& \text { no pau, no pau } \\
& \text { ele fura a auvre } \\
& \text { até mesmo o nó } \\
& \text { no pau, no pau } \\
& \text { ele fura a auvre } \\
& \text { fura até cansar } \\
& \text { para fazê a casa dele } \\
& \text { dir. o pessoar } \\
& \text { (Composição de Mestre Biri) }
\end{aligned}
$$

A cena do carimbó pede a benção para reverenciar todos os seus Mestres, dentre eles Mestre Verequete, com muitas composições registradas em LPs e em dois CDs lançados no mercado. Dentre suas canções, vale destacar aqui Sereia do Mar e Pescador:

\section{Sereia do Mar}

Eu sou a sereia do mar

Eu tô deitada na areia

Tô ouvindo teu cantar

Este carimbó é muito quente

Da cintura pra baixo eu sou peixe

Da cintura pra cima eu sou gente

No meu barco à vela

Viajo a noite inteira

Com o poderio da sereia

Enfrento a cachoeira

\section{Pescador}

Eu tava pescando, morena

Com a linha na mão

Errei uma pescada, morena

Puxei um tubarão

Ah! Como é bom pescar

Na beira mar

Em noite de luar

(Composição de Mestre Verequete)

5 Considerado o carimbó raiæp pela utilização do instrumental tradicional: tambores/curimbós, maraca, milheiro, reco-reco e banjo. 
Vale atentar para as referências explícitas aos animais, ao ato de pescar e aos encantados ${ }^{6}$. Essas referências retornam nas letras de Mestre Lucindo:

\title{
Pescador, pescador
}

\author{
Pescador, pescador por que é que no mar não tem jacaré, \\ Pescador, pescador por que foi que no mar não tem peixe boi \\ Eu quero saber a razão que no mar não tem tubarão, \\ Eu quero saber porque é que no mar não tem jacaré. \\ Ab! Como é bom pescar, à beira mar \\ Em noite de luar \\ (Composição de Mestre Lucindo)
}

De volta ao cenário dos hotéis, as apresentações geralmente acontecem da seguinte forma: primeiro os músicos se posicionam com os seus instrumentos, o coordenador do grupo então apresenta os músicos um a um, feito isso, começam imediatamente a tocar. Os dançarinos, por sua vez, entram em círculo girando todos no mesmo sentido e enfileirados, e fazem movimentos como se remassem, a cada verso os movimentos correspondem à cena cantada. É assim a dança começa, com solo de flauta e requebros das dançarinas, quando entra a voz do cantor e o marcador bate palmas para cadenciar o ritmo. Há momentos em que os casais se abaixam e se levantam alternadamente, num movimento que lembra o balançar da maré7.

A indumentária do carimbó se diferencia pelo sexo dos dançarinos, em geral as mulheres trazem flor no cabelo solto, blusa de cambraia, saia florida bem rodada, pés descalços e colares de contas coloridas. Os homens vestem calça curta, calça pescador, blusa com a mesma estampa da saia das mulheres, amarrada à cintura e aberta para cima e pés descalços. Os músicos vestem calça, blusa estampada, chapéu de palha e pés descalços (Imagem 2). Depois de cada dança, os integrantes do grupo convidam e acompanham as pessoas no salão para dançar.

Imagem 2 - Grupo Cruzeirinho no Festival da Amizade (2015), em Cachoeira do Arari, Marajó (PA).

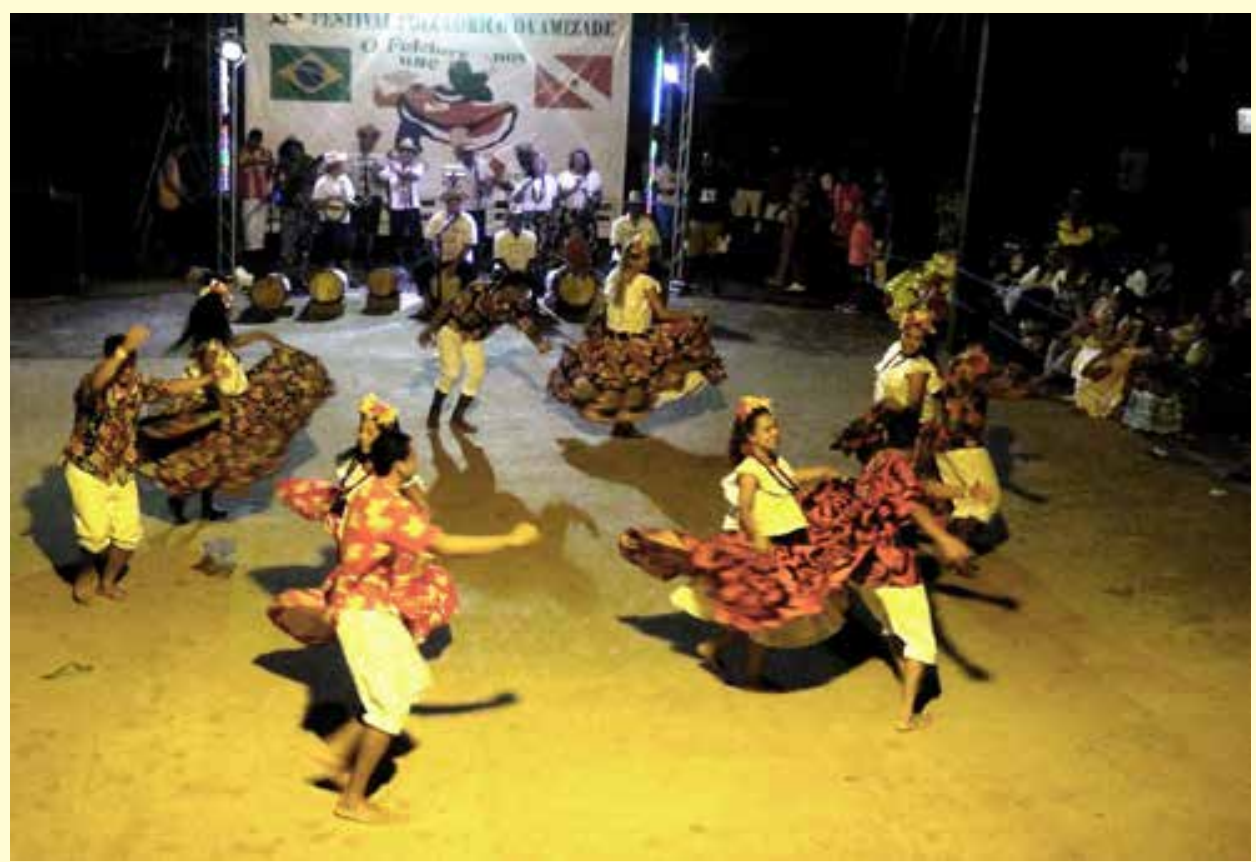

Fonte: Monique Sobral (acervo pessoal).
Atualização do carimbó através do turismo e da indústria cultural

Novos compositore surgiram no cenário musical paraense, que readaptam temas regionais e da cultura popular como boi, carimbó e guitarrada, numa fusão com improvisações em shows e participação de músicos antigos, que produz ritmos regionais sampleados e misturados ao rock e ao pop. Com efeito, Lú Guedes e Maria Fecha a Porta (grupo que lançou $\mathrm{CD}$ independente em 2002), e Cravo Carbono (com o CD Peixe Vivo, lançado

6 Entidades cultuadas nos rituais amazônicos ou mesmo que povoam os imaginários, geralmente híbridas, referenciadas em dimensões não terrenas e também não celestiais. Em alguns estudos, os encantados são caracterizados como seres invisíveis que habitam as regiões subaquáticas e são conhecidos também como caruanas (MAUÉS, 1990).

7 Quando da enchente e da vazante dos rios da Amazônia. 
em 2001), prepararam o terreno para novos personagens nessa cena, que a partir de 2010 ganharam destaque, como os artistas Gaby Amarantos, Felipe Cordeiro e Aíla.

O carimbó é, desde a raiz, uma das formas de lazer do povo paraense, trazendo as vivências cotidianas e de trabalho para o âmbito dessa festa popular. De acordo com Salles e Salles (1969, p. 259), é "o divertimento que mais anima as populações dessa região" sendo dançado nas muitas festas realizadas pelas populações da Amazônia paraense. O uso dessa expressão cultural pela atividade turística faz com que seja possível perceber algumas modificações importantes. O carimbó não é mais dançado apenas nas festas das comunidades, mas também nos salões dos hotéis e/ou em festivais programados. Ao dançar para ganhar dinheiro, o lazer do caboclo se torna trabalho, uma vez que as apresentações são pagas, ainda que os cachês permaneçam baixíssimos. O ritmo do carimbó, agora, é rápido e os turistas são chamados a participar. O que outrora era lazer, dançado em todas as festas, transforma-se em espetáculo e cada apresentação demanda alguma produção, ainda que pequena. Assim, o turismo transforma o brincante em componente de grupo parafolclórico, isto é, em trabalhador, o que é um primeiro movimento redutor.

Para Magnani (1984) a festa na cidade marca a combinação do passado rural com o presente urbano. No rural, ela mantém níveis de relacionamento e pode ter vários papéis, não só a (re)afirmação da identidade e (re)conhecimento, mas também de resistência ao externo, venha ele de onde vier, mesmo da atividade turística. No que se refere ao carimbó, notamos a nítida interferência turística em sua criação e apresentação. Nessa lógica, o trabalho de Maciel (1983) demonstra como o carimbó ganhou, na década de 1970, o meio urbano, ao ser dançado nos bares e casas noturnas de Belém, tocado em rádios e apresentado em programas de televisão. Consumo este que se repete na década 1990, quando vários conjuntos musicais reinserem o carimbó na mídia, identificação possível também nos modismos e nas tendências que acompanha hoje os ritmos musicais no Brasil.

A chamada cultura popular se modifica segundo ritos que permanecem e se transformam em espetáculos e outros que desaparecem por completo. No Marajó, por exemplo, a atividade turística, em espaços como os hotéis, financia o carimbó, e isso expõe dois motivos: primeiro, o baixo valor dos cachês e, segundo, a exigência do turista pelo exótico, uma vez que ele não sai de casa para consumir um produto que já possui. Nessa lógica, a cultura popular entra no circuito do mercado de bens culturais através da atividade turística:

A política de turismo tem um impacto importante no processo de mercantilização da cultura popular. Não é por acaso que as Casas de Cultura Popular, sobretudo no Nordeste, se encontram sempre associadas às grandes empresas de turismo, que procuram explorar as atividades folclóricas e os produtos artesanais (ORTIZ, 1994, p. 46).

Vem daí a concepção de nicho de cultura, exatamente pela organização da cultura promovida pelo estado e preocupada com a manutenção das tradições e a proteção da identidade nacional brasileira. Essa ideia necessita de uma base material para se reproduzir, instituições e espaços onde a memória possa ser ritualizada e a cultura preservada na sua autenticidade (ORTIZ, 1994, p. 107). Esse conceito envolveria, assim, os espaços organizados de manifestação da cultura, construídos para funcionar apenas com essa finalidade, como espaços de nichos: museus, centros culturais, academias, clubes etc.

Com efeito, em Soure, no Marajó, notamos a transformação espacial e de ocorrência das atividades culturais que, num primeiro momento, implica no carimbó dançado nas festas privadas e públicas dos habitantes da cidade. Como nos relatam moradores antigos, o carimbó era tocado pelos conjuntos que animavam casamentos, batizados, aniversários juntamente com outros ritmos da época. E num segundo momento, encontramos o carimbó no clube ou no parque de exposições durante a feira agropecuária. Isso significa que o carimbó está deixando as casas e as festas privadas, para se articular conforme a organização da cultura promovida pelas prefeituras e, assim, se apresentar sob a forma de grupos parafolclóricos.

Se o carimbó alcança os centros culturais ao migrar para espaços próprios, o turismo, por sua vez, atrai a manifestação para si através da possibilidade de um retorno financeiro rápido. O carimbó migra, então, para os guetos turísticos, que são os espaços e equipamentos criados especificamente para o turismo. Os guetos turísticos são

[...] reservas artificiais criadas especialmente para os turistas e construídas sob medi-

da. Esta categoria compreende todos estes novos complexos hoteleiros, estas cidades, 
parques, loteamentos de férias que não nasceram do desenvolvimento de um vilarejo, mas foram plantadas bem no meio de um prado nos Alpes ou à beira de uma bela praia, não importa qual seja (KRIPPENDORF, 1987, p. 68).

Tais locais artificiais são melhor representados pelos complexos de entretenimento, lazer e hospedagem, como os parques temáticos (Disney World) ou grandes complexos hoteleiros (Clube Méditerraneé), totalmente turistificados:
A versão mais perfeita do turismo em guetos é certamente o que o Club Méditerraneé desenvolveu. Coberto de sarcasmo e menosprezo por um imenso número de espíritos críticos, ele é adorado por seus adeptos que fielmente permanecem clientes. [...] A pequena cidade do clube é protegida do exterior através de uma cerca, uma barreira na entrada e uma vigilância rigorosa, para que as pessoas em férias possam se divertir sem sofrer nenhuma perturbação (KRIPPENDORF, 1987, p. 69).

Os guetos turísticos expandem seus raios de ação para fora de seu espaço físico e influenciam imediações para criar espaços desterritorializados:
Os países turísticos são um só país, em todos se fala inglês, existe um cardápio inter- nacional, pode-se alugar carros idênticos, ouvir a música da moda e pagar com um cartão American Express. Mas para se convencer as pessoas a fim de que se deslo- quem até hotéis remotos não basta oferecer-lhes a reiteração dos seus hábitos, [...] é útil que se mantenham cerimônias "primitivas", objetos exóticos e povos que os ofereçam barato (CANCLINI, 1983, p. 67).

O incremento do artesanato em países industrializados revela, enfim, que o "progresso" econômico moderno não impõe eliminar forças produtivas que não servem diretamente para a sua expansão se essas forças tornam coeso um setor numeroso de consumidores e, ainda, satisfazem necessidades setoriais e/ ou de uma reprodução equilibrada do sistema. Ao contrário e de forma complementar, a reprodução das tradições não exige fechar-se à modernização, afinal "a reelaboração heterodoxa - mas autogestiva - das tradições pode ser fonte simultânea de prosperidade econômica e reafirmação simbólica” (CANCLINI, 1997, p. 238-239).

Consoante às conclusões de Canclini, Oliveira (1996) mostra que as situações concretas por ela estudadas esboçam um contexto em que a oposição simplificadora de uma suposta homogeneidade nacional (de um suposto sentimento nacional) versus uma heterogeneidade regional, encobre um complexo universo social. E ainda ressalta:

\begin{abstract}
A acumulação capitalista continua a engendrar novas classes trabalhadoras dispersas no mundo. Estas classes trabalhadoras, diversificadas cultural e socialmente, inserem-se numa hierarquia política e econômica variável. Importante notar que a difusão do capitalismo cria nos contextos particulares, unidades mais amplas que reproduzem a relação capital trabalho. Da mesma forma, cria e recria a diversidade, acentuando a oposição e segmentação social, mesmo tendo um caráter unificador (OLIVEIRA, 1996, p. 114115).
\end{abstract}

Afinal, a quem o turismo serve? Que relações de poder ele trava com a cultura popular? O turismo a priori serve ao capital e está indiscutivelmente inserido nas leis de regulação do mercado, já que diversas expressões culturais são rearticuladas para serem colocadas à venda e comporem produtos turísticos. A mercadorização de aspectos da vida pelo turismo é evidenciada abaixo:

as pessoas da cidade levam sua escala de valores próprios. Fortalecidos pelo dinheiro e nível educacional, em geral, melhor, elas se sentem superiores e se apropriam do espaço rural com fins comerciais e recreativos. A paisagem e os homens se tornam bens de consumo (KRIPPENDORF, 1987, p. 96-97). 
Mesmo assim, formas alternativas de turismo, como o turismo de base comunitária, aparecem atualmente para tratar essas expressões sem tanta interferência do mercado.

Com ou sem o turismo e a indústria cultural, as expressões da cultura popular continuam se afirmando, embora sejam consideradas culturas subalternas ou não atuais, indicando resistências e sobrevivências. Mesmo que a cultura popular ainda seja vista como um resíduo anacrônico ou simples reminiscência de interesse folclórico e turístico, "nem a modernização exige abolir as tradições, nem o destino fatal dos grupos tradicionais é ficar de fora da modernidade" (CANCLINI, 1997, p. 239).

Na existência centenária do carimbó, é possível enxergar sua transformação desde quando clandestino e considerado proibido e imoral, às reuniões na sede dos grupos, nas festividades mais específicas, até os ambientes turísticos. Nessa paisagem, vale destacar o movimento social organizado através da Campanha do Carimbó, que reúne, além da comunidade carimbozeira do Pará, agentes culturais e artistas de todo o Brasil, com o objetivo de consolidar a valorização do carimbó, principalmente através ações pós-registro, que perpetuem, depois do registro no Iphan, a constante legitimação dessa importante expressão cultural. Em $11 \mathrm{de}$ setembro de 2014, o Conselho Consultivo do Patrimônio Cultural aprovou por unanimidade o registro do carimbó como Patrimônio Imaterial Brasileiro (BRASIL, 2015), cujo primeiro aniversário foi comemorado no último dia 11 de setembro, em Belém (Imagem 3).

Imagem 3 - Ato em comemoração ao $1^{\circ}$ ano do registro do Carimbó como Patrimônio Cultural Imaterial Brasileiro (2015).

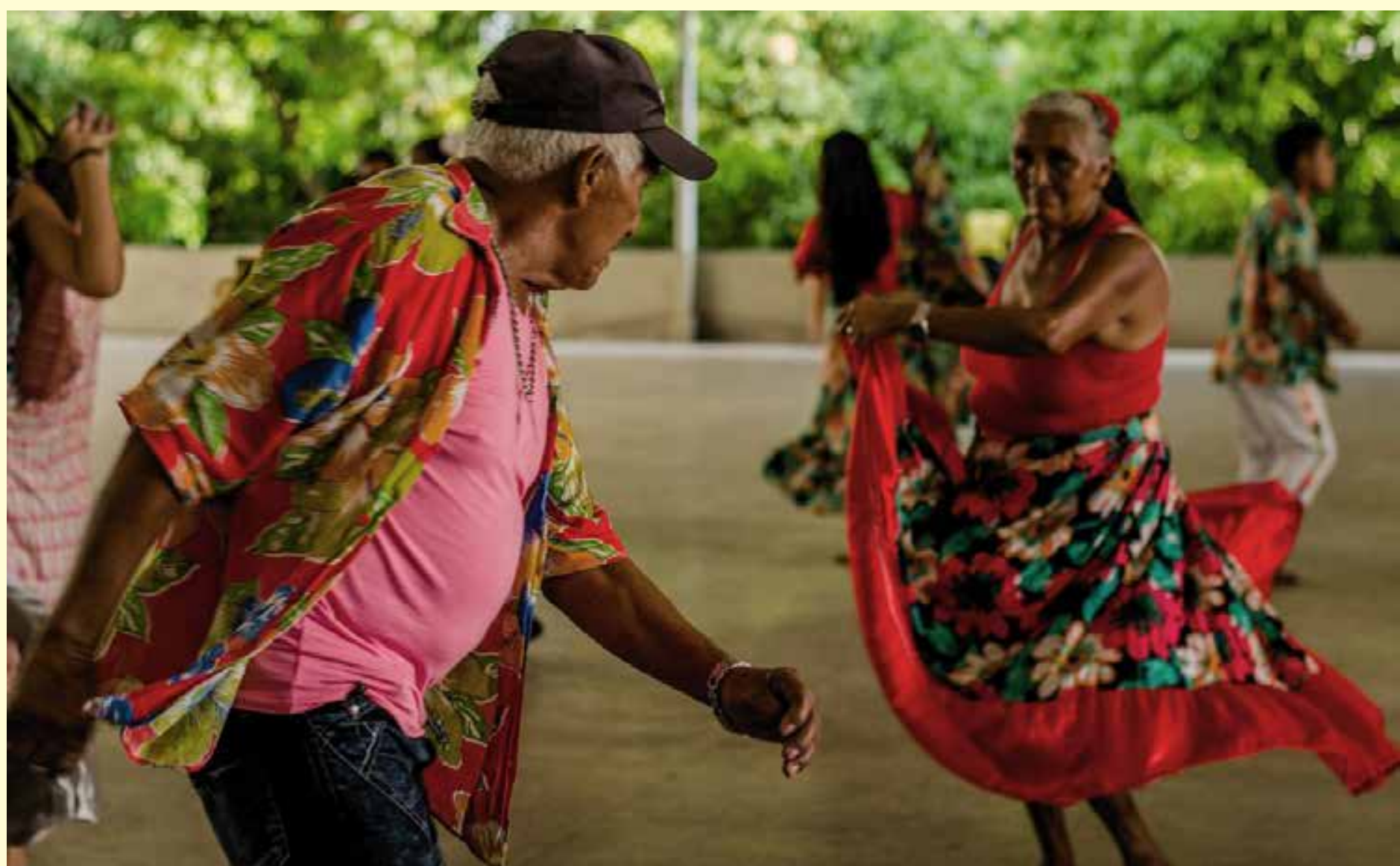

Fonte: Pierre Azevedo (acervo pessoal).

\section{Considerações finais}

O carimbó demonstra ser, na sua trajetória como expressão simbólica da cultura popular paraense, exemplo da complexidade da atualização cultural. Isso é indicado inicialmente pela sua origem, dentre muitas, nos batuques dos negros do Umarizal (bairro de Belém), alvo de proibições no final do século XIX e inicio do século XX. A inclusão de instrumentos como o banjo e a flauta, principalmente sob a influência das bandas e grupos que ocupavam os teatros da capital do estado nas décadas de 40 e 50 do século passado, começou a dar ao batuque as nuances melódicas que tem hoje. A proliferação de grupos e a gravação de vá- 
rios LPs durante as décadas de 1970 e 1980 colocaram o carimbó nas rádios, programas de televisão, festas sociais, apresentações e shows.

Esse percurso manteve o carimbó nas paradas de sucesso do Pará, pelo menos durante um certo tempo, até sua retração no final dos anos 1990 e início dos anos 2000. Atualmente, um novo cenário se desenha através do processo de registro como Patrimônio Cultural Brasileiro, originário de uma campanha que envolveu diversos atores. Interessante notar que, no início, o único objetivo da Campanha do Carimbó era alcançar o registro, porém, a partir de 2008, houve a compreensão de que o registro era apenas uma das metas num horizonte de conexão em rede regional/nacional para discutir e fortalecer a cultura popular e tradicional em todos os níveis da federação (BOGÉA, 2014).

A Campanha Carimbó Patrimônio Cultural Brasileiro nasce de iniciativa da comunidade de Santarém Novo, através da Irmandade de São Benedito, com o objetivo de consolidar a valorização do carimbó, que teve finalmente o registro alcançado em setembro de 2014. Isso demonstra o amadurecimento de um movimento social que, em junho de 2015, organizou o $1^{\circ}$ Congresso Estadual do Carimbó para construção da agenda prioritária da salvaguarda após o registro, reinvindicações que foram encaminhadas ao Iphan nesse mesmo ano. Dez anos após o pedido de registro junto ao Iphan, o carimbó recebeu, em novembro de 2015, em uma cerimônia pública, o Título de Patrimônio Cultural do Brasil.

\begin{abstract}
Segundo Isaac Loureiro ${ }^{8}$, a campanha para o registro junto ao Iphan - como desdobramento de ações que já aconteciam em Santarém Novo - começa em 2005. Quando do Fest Rimbó ${ }^{9}$, a Irmandade de São Benedito promove Seminário para discutir os rumos do carimbó inspirado pelo tema "O Carimbó como Identidade Cultural do Povo da Amazônia", que contou com a participação de vários grupos de carimbó presentes no festival, secretários de cultura dos municípios da região (nordeste paraense), Iphan, representação regional norte do Ministério da Cultura e o governo do estado através do IAP ${ }^{10}$ e Fundação Curro Velho, vinculados à Secretaria de Estado de Cultura do Pará (Secult). No momento desse primeiro debate, ao reunir todos esses atores em Santarém Novo, a fala do Iphan - ao apresentar sua política de patrimônio e experiências de registro de outras manifestações culturais, como jongo, frevo, samba de roda e o samba carioca - ao apontar a possibilidade do registro, motiva as comunidades e grupos das várias manifestações do carimbó paraense ali presentes a compreender esse ritmo como integrante desse universo do patrimônio imaterial brasileiro (BOGÉA, 2014, p. 6).
\end{abstract}

Assim, o carimbó paraense atualiza de forma errática, diversa e com certo sucesso sua forma de permanecer no imaginário da população paraense. Os desdobramentos da política pública de salvaguarda apontam para uma possibilidade do carimbó ultrapassar a dependência do turismo e da indústria cultural, principalmente no contexto da pulverização das produções na era da rede mundial de computadores. Assim, mais do que resistência, é cultura que se atualiza, híbrida, nas possibilidades de garantir sua própria sobrevivência.

\title{
Referências:
}

BOGÉA. E. A Cultura no Brasil pós-2003, um norte: Carimbó Patrimônio Cultural Brasileiro. In: SEMINÁRIO INTERNACIONAL DE POLÍTICAS CULTURAIS, 5, 2014, Rio de Janeiro. Anais... Rio de Janeiro: Fundação

8 Isaac Loureiro é coordenador da Campanha do Carimbó.

9 Festival de Carimbó de Santarém Novo nasceu em 2002 por iniciativa da sociedade civil organizada no Fórum do Desenvolvimento Local Integrado e Sustentável cujo debate incluiu o campo cultural porque reconhecidamente uma das forças dinâmicas do município. O carimbó como expressão maior da cultura local inspira organizar um evento capaz de atrair a atenção da região (nordeste paraense) para Santarém Novo, com vistas a motivar a cena do carimbó, principalmente pela existência de muitos grupos ainda desconhecidos do público que mesmo em condições precárias mantém uma produção atual. No interior do Fest Rimbó, como evento agregador do carimbó no estado do Pará, nasce em 2006 o Movimento Carimbó Patrimônio Cultural Brasileiro, o que transforma o Fest Rimbó em importante momento de articulação anual da Campanha do Carimbó.

10 Instituto de Artes do Pará, extinto na reforma administrativa do governo do estado em janeiro de 2015. 
Dossiê

Casa de Rui Barbosa, 2014. p. 1 - 16. Disponível em: < http://culturadigital.br/politicaculturalcasaderuibarbosa/ files/2014/06/Eliana-Bog\%C3\%A9a.pdf>. Acesso em: 09 nov. 2015.

BRANDÃO, Carlos Rodrigues. O Divino, o Santo e a Senhora. Rio de Janeiro: FUNARTE, 1978.

BRASIL. Ministério da Cultura. Notícias. Carimbó é agora patrimônio imaterial brasileiro, 11 set. 2014. Disponível em: < http://www.cultura.gov.br/noticias-destaques/-/asset publisher/OiKX3xlR9iTn/content/carimbo-e-agora-patrimonio-imaterial-brasileiro/10883>. Acesso em: 2 ago. 2015.

CANCLINI, Néstor García. As culturas populares no capitalismo. São Paulo: Brasiliense, 1983.

. Culturas Hibridas: estratégias para entrar e sair da modernidade. São Paulo: Edusp, 1997.

. Consumidores e Cidadãos. Rio de Janeiro: Ed. UFRJ, 1995.

FIGUEIREDO, S. L.; TAVARES, A. E. P. Mestres da Cultura. Belém: EDUFPA, 2006.

FIGUEIREDO, S.L. Círio de Nazaré, festa e paixão. In: FIGUEIREDO, S. L. (Org.). Círio de Naz̧aré, festa e paixão. Belém: UFPA, 2005. p. 19-39. . Ecoturismo, Festas e Rituais na Amazônia. Belém: NAEA/UFPA, 1999.

. Turismo e Cultura: mudança cultural em Soure (Marajó/PA) em decorência da exploração do ecotursimo. 1998. Dissertação (Mestrado em Planejamento do Desenvolvimento) - Universidade Federal do Pará, Belém. 1998. FURTADO, Lourdes G. Curralistas e Redeiros de Marudá: pescadores do litoral do Pará. Belém: MPEG, 1985.

INSTITUTO DO PATRIMÔNIO HISTÓRICO E ARTÍSTICO NACIONAL (Iphan). Inventário Nacional de Referências Culturais (INRC) Carimbó. Dossiê Iphan Carimbó. Belém-PA, 2013.

GABBAY, Marcelo M. O carimbó marajoara: por um conceito de comunicação poética na geração de valor comunitário. 2012. Tese (Doutorado em Comunicação e Cultura) - Universidade Federal do Rio de Janeiro, Rio de Janeiro. 2012.

KRIPPENDORF, Jost. Les Vacances et Après? Pour une nouvelle compréhension des loisirs et des voyages. Paris: L'Harmatan, 1987.

MACIEL, Antônio Francisco. Carimbó, um canto caboclo. 1983. Dissertação (Mestrado em Letras) - Universidade Estadual de Campinas, Campinas. 1983.

MAGNANI, José G. C. Festa no Pedaço: cultura popular e lazer na cidade. São Paulo: Brasiliense, 1984.

MAUÉS, Raymundo Heraldo. A Ilha Encantada: medicina e xamanismo numa comunidade de pescadores. Belém: EDUFPA, 1990.

OLIVEIRA, Ana Gita. O Mundo Transformado: um estudo da cultura de fronteira no Alto Rio Negro. Belém: MPEG, 1995.

OLIVEIRA, Roberto Cardoso de. Identidade, Etnia e Estrutura Social. São Paulo: Pioneira Editora, 1978.

ORTIZ, Renato. Cultura Brasileira e Identidade Nacional. 4. ed. São Paulo: Brasiliense, 1994.

SALLES, Vicente; SALLES, Marena Isdebski. Carimbó: trabalho e lazer do caboclo. Revista Brasileira de Folclore, Rio de Janeiro, v. 9, n. 25, p. 257-282, set./dez. 1969.

TURNER, V. O Processo Ritual. Estrutura e Anti Estrutura. Petrópolis: Vozes, 1974. 